\title{
Expression and Evolution of Short Wavelength Sensitive Opsins in Colugos: A Nocturnal Lineage That Informs Debate on Primate Origins
}

\author{
Gillian L. Moritz • Norman T.-L. Lim • \\ Maureen Neitz $\cdot$ Leo Peichl $\cdot$ Nathaniel J. Dominy
}

Received: 19 December 2012/ Accepted: 29 March 2013/Published online: 17 April 2013

(C) The Author(s) 2013. This article is published with open access at Springerlink.com

\begin{abstract}
A nocturnal activity pattern is central to almost all hypotheses on the adaptive origins of primates. This enduring view has been challenged in recent years on the basis of variation in the opsin genes of nocturnal primates. A correspondence between the opsin genes and activity patterns of species in Euarchonta-the superordinal group that includes the orders Primates, Dermoptera (colugos), and Scandentia (treeshrews) — could prove instructive, yet the basic biology of the dermopteran visual system is practically unknown. Here we show that the eye of the Sunda colugo (Galeopterus variegatus) lacks a tapetum lucidum and has an avascular retina, and we report on the
\end{abstract}

Electronic supplementary material The online version of this article (doi:10.1007/s11692-013-9230-y) contains supplementary material, which is available to authorized users.

G. L. Moritz $(\bowtie) \cdot$ N. J. Dominy

Department of Biological Sciences, Dartmouth College,

The Class of 1978 Life Sciences Center, 78 College Street,

Hanover, NH 03755, USA

e-mail: gillian.1.moritz@dartmouth.edu

N. T.-L. Lim

Department of Wildlife, Fish and Conservation Biology,

University of California, One Shields Avenue, Davis,

CA 95616, USA

M. Neitz

Department of Ophthalmology, University of Washington, Box 356485, 1959 NE Pacific Street, Seattle, WA 98195, USA

L. Peichl

Max Planck Institute for Brain Research, Deutschordenstrasse 46, 60528 Frankfurt am Main, Germany

N. J. Dominy $(\square)$

Department of Anthropology, Dartmouth College,

6047 Silsby Hall, Hanover, NH 03755, USA

e-mail: nathaniel.j.dominy@dartmouth.edu expression and spectral sensitivity of cone photopigments. We found that Sunda colugos have intact short wavelength sensitive (S-) and long wavelength sensitive (L-) opsin genes, and that both opsins are expressed in cone photoreceptors of the retina. The inferred peak spectral sensitivities are 451 and $562 \mathrm{~nm}$, respectively. In line with adaptation to nocturnal vision, cone densities are low. Surprisingly, a majority of S-cones coexpress some L-opsin. We also show that the ratio of rates of nonsynonymous to synonymous substitutions of exon 1 of the S-opsin gene is indicative of purifying selection. Taken together, our results suggest that natural selection has favored a functional S-opsin in a nocturnal lineage for at least 45 million years. Accordingly, a nocturnal activity pattern remains the most likely ancestral character state of euprimates.

Keywords Retina - Visual pigment - Dermoptera . Scandentia $\cdot$ Primates

\section{Introduction}

All organisms must obtain information about their physical environment and respond to changing conditions such as circadian variation in light intensity and spectral composition. For most vertebrates, image-forming vision is central to survival, underlying fundamental behaviors such as predator avoidance, foraging, and mate recognition. Thus, it stands to reason that the genes that encode visionmediating proteins are under strong selective pressure, and that molecular changes to these genes are ultimately advantageous to the survival of the organism (Davies 2011). In fact, molecular adaptations to diverse light environments are prevalent across vertebrates, determining 
the number, type, and spectral sensitivities of visual pigments. This strong link between a visual system and its predominant photic environment has practical use for inferring ancestral behaviors, including the origin and evolution of each major vertebrate radiation (Davies et al. 2012)

The dichromatic color vision of most mammals is based on the presence of two cone opsins - the long wavelength sensitive (L-) opsin and the short wavelength sensitive (S-) opsin (Peichl 2005). A puzzling exception to this pattern is the loss of the S-opsin, and hence the absence of color vision, or monochromatic vision, in a number of - mostly nocturnal-mammals (review: Jacobs 2013). It has been tempting to link the L-cone monochromacy of these species with dark (scotopic) light environments, and to assume that relaxation of natural selection is the cause of disabling mutations on the S-opsin gene. This hypothesis is weakened in part by variation among closely related species with similar scotopic behaviors; for instance, the Syrian golden hamster, Mesocricetus auratus, is an L-cone monochromat, whereas the Siberian dwarf hamster, Phodopus sungorus, has both opsins intact (Calderone and Jacobs 1999). Among bats, the S-opsin gene has been lost in some lineages, while both cone opsin genes have been maintained over many millions of years in others (Wang et al. 2004; Müller and Peichl 2005; Müller et al. 2007, 2009; Zhao et al. 2009a, b). This latter finding suggests that dichromatic vision is advantageous for some nocturnal species; however, the functional and adaptive significance of such vision is uncertain. Importantly, a similar pattern has been reported among nocturnal primates and it has had the effect of fueling debate focused on primate origins.

\section{Euprimate Origins}

The common ancestor of euprimates (primates of modern aspect or crown-clade primates) is often reconstructed as nocturnal (Martin 1990; Heesy and Ross 2001; Ravosa and Savakova 2004; Martin and Ross 2005; Ravosa and Dagosto 2007; Ross and Kirk 2007). As a result, a nocturnal activity pattern is central to almost all hypotheses on the adaptive origins of primates (Cartmill 1992). This enduring view has been challenged in recent years on the basis of variation in the cone opsin genes of nocturnal primates (Tan et al. 2005). Specifically, some taxa-the lorisoids, dwarf and fork-marked lemurs, and night monkeys-have lost the functionality of their S-opsin genes and possess monochromatic cone vision (Wikler and Rakic 1990; Jacobs et al. 1996a; Tan et al. 2005; Veilleux et al. 2013). In other lineages-the mouse lemurs, Avahi, Lepilemur, aye-ayes, and tarsiers - the S- and L-opsin genes are intact (Tan and Li 1999; Tan et al. 2005; Melin et al. 2013). The expression of both visual pigments has been verified in two of these taxa (Hendrickson et al. 2000; Dkhissi-Benyahya et al. 2001; Peichl et al. 2001), indicating the potential for dichromatic color vision.

On the assumption that monochromatic vision is favored under nocturnal conditions, Tan et al. (2005) suggested that the common ancestor of euprimates was either cathemeral (arrhythmic) or diurnal, and that living primates represent at least seven independent shifts to nocturnality. Furthermore, some of these shifts must have been relatively recent because genetic drift has yet to result in disabling mutations of the S-opsin genes (Tan et al. 2005). The hypothesis that intact S-opsin genes are functionless anachronisms for all nocturnal species is challenged by evidence of purifying selection at the S-opsin gene locus of tarsiers (Kawamura and Kubotera 2004) and aye-ayes (Perry et al. 2007). These findings indicate that at least some nocturnal primate species benefit from having an intact S-opsin gene, although the functional advantages are uncertain (Melin et al. 2012). Jacobs (2008) has given a critical overview of this controversy.

If the behavior of tarsiers (Tarsius) can be inferred from orbital morphology, the hyper-enlarged orbits of Tarsius eocaenus from the Middle Eocene suggests that the S-opsin genes of tarsiers have survived 45 million years of nocturnality intact (Rossie et al. 2006). Such antiquity of color vision genes at the genus taxonomic level is seldom paralleled. Thus inferences on the evolution and function of S-opsin genes, and therefore the origins of primates, can be tenuous. Yet the fossil record of the superordinal group Euarchonta-the orders Primates, Dermoptera (colugos), and Scandentia (treeshrews) — is instructive, and it suggests that extant colugos are 'living fossils' that have scarcely changed since the Middle Eocene (Ducrocq et al. 1992; Marivaux et al. 2006). The implication of longstanding nocturnality in this lineage agrees well with the nuclear architecture of their rods (Solovei et al. 2009; Perry and Pickrell 2010), and motivates the present study of their opsins.

\section{Colugos: Systematics, Anatomy, and Behavior}

Although the internal structure of Euarchonta is unresolved (Martin 2008), most recent evidence favors a sister grouping between colugos and primates (Fig. 1a; Janečka et al. 2007; Meredith et al. 2011; Perelman et al. 2011) or the concept of Sundatheria (Dermoptera + Scandentia) as the sister taxon to Primates (Bloch et al. 2007; O'Leary et al. 2013). Presently, there are two recognized species of colugo, now in separate genera: the Sunda colugo Galeopterus variegatus (formerly Cynocephalus variegatus) and the Philippine colugo Cynocephalus volans (Janečka et al. 2008). Both species are nocturnal. A distinctive feature of colugos is the large gliding membrane 

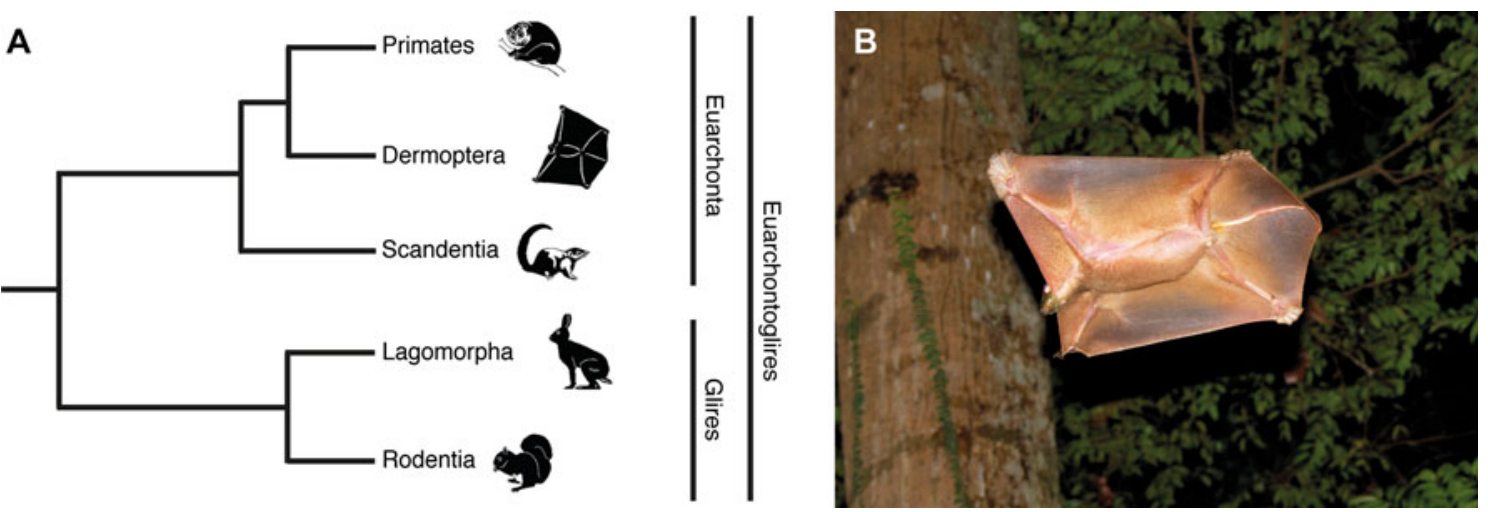

Fig. 1 a Phyletic position of colugos (Dermoptera) within the grandorder Euarchonta and superorder Euarchontoglires. Modified from Martin (2008). b Sunda colugo (Galeopterus variegatus) in the Bukit Timah Nature Reserve, Singapore (photograph by Norman T.-L. Lim)

(patagium) that practically surrounds the entire body. As a result, colugos are sometimes called 'flying lemurs', butas Simpson (1945) noted wryly-they "are not lemurs and [they] cannot fly". Colugos differ from other gliding mammals in that the patagium extends between the hind limbs and the short tail (Fig. 1b), including even the fingers and toes (Beard 1993).

They also possess serrated upper incisors and procumbent lower incisors that are uniquely subdivided into as many as 15 comb-like tines (Rose et al. 1981). The function of these tines is uncertain, but they appear to support grooming and foraging behaviors (Aimi and Inagaki 1988). The diet of colugos consists mainly of leaves, to which they have corresponding digestive adaptations (Wischusen et al. 1994). In general, the behavioral ecology of colugos is poorly known, although recent field studies are yielding valuable new information (Wischusen and Richmond 1998; Mendoza and Custodio 2000; Agoramoorthy et al. 2006; Lim 2007; Dzulhelmi and Abdullah 2009; Byrnes et al. 2008, 2011a, b).

Colugos are thus unique nocturnal mammals that provide an important comparative context for testing hypotheses related to the color vision and origins of primates. Here we report on the expression and inferred spectral sensitivity of cone photopigments in the retinae of Sunda colugos ( $G$. variegatus). Our results fill a crucial phylogenetic void and provide new insight into how and why $\mathrm{S}$-opsin genes are maintained in a nocturnal milieu.

\section{Materials and Methods}

\section{Animals and Tissue Preparation}

A population of Sunda colugos inhabits the forests of Singapore (Lim and Ng 2010; Lim et al. 2013) and animals are occasionally found dead by members of the public and donated to the Raffles Museum of Biodiversity Research,
National University of Singapore. Here we report on the retinal histology and opsins of three such animals, two adult males and a juvenile female (accession nos. ZRC.4.8122, ZRC.4.8138, ZRC.4.8186, respectively). Tissue preservation varied as a function of how soon the eyes were enucleated and fixed post mortem. Our best results were obtained from eyes that were fixed within hours of death (e.g., ZRC.4.8138). In each case, the eyes were marked at their dorsal pole for orientation and cut slightly open at the corneal rim for better fixative penetration, and fixed in conventional $10 \%$ formalin in physiological saline for several days to several weeks. The eyes were then transferred to $0.1 \mathrm{M}$ phosphate buffer $(\mathrm{PB}, \mathrm{pH}$ 7.4) with $0.05 \%$ sodium azide and stored at $4{ }^{\circ} \mathrm{C}$ until processing. Eye dimensions were recorded before the eye was cut fully open around the cornea. The cornea, lens and vitreous were removed, and the retina was carefully isolated from the eyecup.

\section{Retinal Histology and Opsin Immunohistochemistry}

For assessment of general retinal morphology, pieces of retina were embedded in Epon, sectioned vertically (i.e. perpendicular to the retinal layers) at $1 \mu \mathrm{m}$, and stained with toluidine blue. For assessment of retinal vascularization, a retinal segment measuring ca. $5 \times 5 \mathrm{~mm}$ and containing the optic nerve head was stained with a $3,3^{\prime}$ diaminobenzidine (DAB) reaction to selectively visualize the endogenous peroxidase in the vasculature. Following the protocol of Peichl (1992), the retinal piece was washed in $\mathrm{PB}$ and then incubated in a solution of $0.05 \% \mathrm{DAB}$ and $0.01 \%$ hydrogen peroxide in PB until the peroxidase reaction was fully developed (ca. $10 \mathrm{~min}$ ). The reaction was stopped by several washes in PB; the tissue was then flat-mounted on a slide and coverslipped with an aqueous mounting medium (AquaPoly/Mount, Polysciences Inc., Warrington, USA). 
Immunohistochemistry was performed on frozen sections and on unsectioned retinal pieces. The tissue was cryoprotected by successive immersion in 10, 20 and $30 \%$ $(w / v)$ sucrose in PB. For sections, the retina was transferred from $30 \%$ sucrose to tissue-freezing medium (ReichertJung, Bensheim, Germany), sectioned vertically at a thickness of $14 \mu \mathrm{m}$ with a cryostat, and collected on SuperFrost slides (Menzel, Braunschweig, Germany). For staining of unsectioned pieces, the tissue was repeatedly shock-frozen and thawed to improve penetration of the antibodies.

Rod opsin (rhodopsin) was detected with the mouse monoclonal antibody rho4D2 (dilution 1:500) provided by R. S. Molday (Hicks and Molday 1986). The S-opsin was detected with the rabbit antiserum JH 455 (dilution 1:5,000) or the goat antiserum sc-14363 (dilution 1:100 or 1:500; Santa Cruz Biotechnology, Heidelberg, Germany), whereas the L-opsin was detected with the rabbit antiserum JH 492 (dilution 1:2,000). The rabbit cone opsin antisera were provided by J. Nathans (Wang et al. 1992). Opsin immunolabeling followed protocols described in Peichl et al. (2005) and Schleich et al. (2010). A brief description of the procedure and controls is given in the Supplemental Material.

\section{Analysis}

Tissue was analyzed with a Zeiss Axioplan 2 microscope equipped with epifluorescence. Micrographs were taken with a CCD camera and the Axiovision LE software (Carl Zeiss Vision, Germany). The images were adjusted for brightness and contrast using Adobe Photoshop 7.0. Rod densities were estimated from outer nuclear layer (ONL) soma counts in vertical cryostat sections labeled for the rod opsin. The density of cones expressing S- and L-opsins in various retinal regions was assessed in PAP-DAB-reacted pieces labeled by $\mathrm{JH} 492$ or $\mathrm{JH} 455$. Counts were made in sample fields with a $\times 40$ or $\times 63$ objective focused on the cone somata labeled by these antisera. This process gave reliable counts in regions where some of the outer segments had been lost due to suboptimal preservation of the retina. No attempt was made to obtain detailed maps of cone topographies. Cone and rod densities were not corrected for shrinkage, which was negligible in the tissues mounted with the aqueous medium.

\section{Cone Opsin Spectral Tuning Sites}

To estimate the spectral sensitivities $\left(\lambda_{\max }\right)$ of the $S$ - and L-opsins, genomic DNA was extracted from the muscle tissue of male ZRC.4.8122 following the methods of Neitz et al. (1991). Among vertebrates, the $\lambda_{\max }$ of the S-opsin is determined by residues present at seven sites (46, 49, 52, 86, 93, 114 and 118) (Shi et al. 2001). In most mammals, a $\lambda_{\max }$ in the ultraviolet (UV, 360-400 nm) or violet-blue $(400-450 \mathrm{~nm})$ region of the spectrum is determined by the residue at site 86 , with Phe (Phe86) conferring UV sensitivity and either Leu, Ser, Tyr or Val causing a shift to longer wavelengths ( 415-440 nm) (Hunt et al. 2004, 2007, 2009). The aye-aye (Daubentonia madagascariensis) is an exception to this pattern; an amino acid change from Thr to Pro at site 93 (denoted Thr93Pro) partly overrides the spectral effects of Phe86, resulting in an intermediate $\lambda_{\max }$ of $\sim 406 \mathrm{~nm}$ (Carvalho et al. 2012).

Similarly, the $\lambda_{\max }$ of the L-opsin pigment can be predicted by residues present at three sites: site 180 encoded by exon 3 and sites 277 and 285 encoded by exon 5 of the L-opsin gene (Neitz et al. 1991). Pigments with the hydroxyl-bearing amino acids (Ser, Tyr, Thr) at sites 180, 277 and 285 have $\lambda_{\max }$ values at relatively longer wavelengths than the corresponding pigments with non-polar amino acids (Ala, Phe, Ala) (Neitz et al. 1991; Merbs and Nathans 1992; Asenjo et al. 1994; Yokoyama and Radlwimmer 2001). The magnitudes of the shifts conferred by the amino acid at position 180 depends on what amino acids are present at the other positions (Neitz and Neitz 2011).

\section{Partial Gene Sequences}

The S-opsin gene was amplified using degenerate primers described previously by Wang et al. (2004) for amplifying the S-opsin genes of bats. Two segments were amplified, Exons 1-4 and Exons 4-5. The colugo S-opsin exon 1-4 segment was amplified in hot start PCR using the ABI Gene Amp XL PCR kit and AmpliWax Gems (ABI, Foster City, USA). The final reaction volume was $100 \mu \mathrm{l}$, with final concentrations of $1.5 \mathrm{mM}$ magnesium acetate, $200 \mu \mathrm{M}$ for each dNTP, and $900 \mathrm{nM}$ for each primer. The PCR product was gel purified and ligated into the pCR2.1 cloning vector using the TA Cloning Kit (Invitrogen, Carlsbad, USA). Multiple individual clones were sequenced using Big Dye Terminator V3.1, and the sequences were used to design colugo-specific S-opsin primers (colugoSFwd1: 5'GCCTT CATGGGCTTTGTCTTCT; colugoSRev1: 5'CCCCCATC ATTCCCTTTCAGTA; colugoSFwd2: 5'TGGGGAAAA GGAGTTTGGTTCT; colugoSRev2: 5'CTGGCTATGCA CATTTCCAGGT). These primers were used to amplify segments of the S-opsin gene from genomic DNA and the PCR products were directly sequenced. Amplifications using the primer pair colugoSFwd1 and colugoSRev1, were in a final reaction volume of $50 \mu \mathrm{l}$, using the ABI AmpliTaq Gold kit. The final concentrations were $1.0 \mathrm{mM} \mathrm{MgCl}_{2}$, $125 \mu \mathrm{M}$ for each of the dNTPs, and $600 \mathrm{nM}$ for each primer. Reactions were incubated at $95{ }^{\circ} \mathrm{C}$ for 9 min followed by 35 cycles of $94{ }^{\circ} \mathrm{C}$ for $30 \mathrm{~s}, 64{ }^{\circ} \mathrm{C}$ for $30 \mathrm{~s}$, and $72{ }^{\circ} \mathrm{C}$ for $30 \mathrm{~s}$. Finally, the reactions were incubated at $72{ }^{\circ} \mathrm{C}$ for $7 \mathrm{~min}$. The same parameters were used for reactions with the primers 
colugoSFwd 2 and colugoSRev2 except that following the initial incubation at $95{ }^{\circ} \mathrm{C}$ for $9 \mathrm{~min}$, reactions were subjected to 35 cycles of $94{ }^{\circ} \mathrm{C}$ for $30 \mathrm{~s}, 64{ }^{\circ} \mathrm{C}$ for $30 \mathrm{~s}$, and $72{ }^{\circ} \mathrm{C}$ for $2 \mathrm{~min}$. PCR products were directly sequenced.

The colugo S-opsin gene exon 4-5 segment was amplified using primers that were described previously (Wang et al. 2004). Each PCR reaction was in a final volume of $50 \mu \mathrm{l}$. Final concentrations and cycling parameters were the same as those described above for primers colugoSFwd1 and colugoSRev1. The PCR product was directly sequenced with the same primers used to amplify it.

Exon 5 of the colugo L-opsin gene was amplified using the ABI AmpliTaq Gold kit. The primers were tcOp5 Fwd 5'GAATCCACCCAGAAGGCAGAG and tcOp5 Rev 5'ACGGGGTTGTAGATAGTGGCA. The final reaction volume was $50 \mu \mathrm{l}$ with a final concentration of $1.0 \mathrm{mM}$ $\mathrm{MgCl} 2,125 \mu \mathrm{M}$ for each of the dNTPs, and $600 \mathrm{~nm}$ each for the forward and reverse primers. Samples were initially incubated at $95{ }^{\circ} \mathrm{C}$ for $9 \mathrm{~min}$ followed by 35 cycles of $94^{\circ}$ for $15 \mathrm{~s}, 59^{\circ}$ for $15 \mathrm{~s}$ and $72^{\circ} \mathrm{C}$ for $30 \mathrm{~s}$. The reactions were then incubated at $72{ }^{\circ} \mathrm{C}$ for $10 \mathrm{~min}$.

PCR products were prepared for sequencing using Centricon 30 filters (Millipore) according to the manufacturer's recommendations. The Big Dye Terminator V3.1 kit $(\mathrm{ABI})$ was used for sequencing, and the reaction products were analyzed on an ABI 3100 capillary sequencer.

\section{Ancestral State Reconstruction}

Comparative sequence data for euarchontans was obtained from GenBank and aligned via ClustalW in MEGA5 (Tamura et al. 2011). The evolutionary history of euarchontan S-opsin genes was inferred using the Neighbor-Joining (NJ) method (Saitou and Nei 1987). The NJ tree and others based on Bayesian estimates of phylogeny from the 10kTrees website (Arnold et al. 2010) were used to construct a composite tree topology for the following species: G. variegatus KC865781; Tupaia belangeri EU487780; Bos taurus AH003442; Daubentonia madagasariensis EF667285; Avahi laniger DQ191893; Propithecus verreauxi DQ191935; Microcebus murinus DQ191922; Eulemur fulvus AB111464; Tarsius bancanus AB111463; Tarsius syrichta DQ191954; Cebus olivaceus AH005810; Pan troglodytes NM_001009127; Homo sapiens U53874; Mus musculus AH005191; Rattus norvegicus NM_031015. Ancestral states were inferred using the Maximum Likelihood method (Nei and Kumar 2000) under the JTT matrix-based model (Jones et al. 1992) in MEGA5 (Tamura et al. 2011).

\section{S-Opsin Gene Sequence Analysis}

Evolutionary patterns of selective constraint on the S-opsin gene (exon 1) were assessed using the Selecton server
(Stern et al. 2007) and the Codeml package in PAML (v4.4) (Yang 1997). PAML uses a maximum likelihood framework to estimate the ratio of non-synonymous to synonymous rates $\left(d_{N} / d_{S}\right.$ or $\left.\omega\right)$ for the entire data set and tree (M0 model), for particular lineages (branch models), for particular codons (sites models), or for particular codons within particular lineages (branch-site models). The $\omega$ value is thought to reflect the degree of evolutionary constraint, or selection pressure on the site class and/or lineage of interest, with $\omega<1$ indicating purifying selection, $\omega=1$ neutral evolution, and $\omega>1$ positive selection. To test for the possibility of branch-specific $\omega>1$, a model in which all branches in the tree are assigned the same $\omega$ (M0) was compared with a model in which specific branches have a different $\omega$ value (two-ratio) (Yang and Nielsen 1998). Models incorporating site classes under positive selection (M2a) were also compared to neutral models (M1a). We calculated the probability that two models should differ in log likelihood as much as observed, with the test statistics following a $\mathrm{x}^{2}$ distribution and degrees of freedom equal to the difference in the number of parameters between the two models.

\section{Results}

General Features of the Eye and Retina

General features of the eye and retina are reported in Table 1 and as Supplemental Material. Inspection of the fundus in opened eyecups revealed no obvious blood vessels emerging from the optic disc or extending across the retina. Hence we stained a piece of central retina including the optic nerve head with a DAB reaction to label blood

Table 1 Eye and photoreceptor properties of the Sunda colugo, $G$. variegatus

\begin{tabular}{ll}
\hline General features & \\
Body weight $(\mathrm{kg})$ & $0.9-1.3$ \\
Eye axial length $(\mathrm{mm}) ; \mathrm{n}=3$ & $15.5 / 15.7 / 16.4$ \\
Eye equatorial diameter $(\mathrm{mm})$ & $16.5 / 17.4 / 19.0$ \\
Corneal diameter $(\mathrm{mm})$ & $13.0 / 14.0 / 14.7$ \\
Lens diameter $(\mathrm{mm})$ & $9.0 / 10.0 / 10.8$ \\
Lens thickness $(\mathrm{mm})$ & $6.4 / 8.3 / 8.0$ \\
Photoreceptors & \\
Rod density estimate $\left(\mathrm{mm}^{-2}\right)$ & $200,000-250,000$ \\
Cone density (mm $\left.{ }^{-2}\right)$ & $\sim 2,500-11,800$ \\
Cone \%age of photoreceptors & $1-5$ \\
Density of L-opsin-expressing cones $\left(\mathrm{mm}^{-2}\right)$ & $\sim 2,400-11,700$ \\
Density of S-opsin-expressing cones $\left(\mathrm{mm}^{-2}\right)$ & $\sim 100-480$ \\
S-cone \%age of cones & $2-9$ \\
\hline
\end{tabular}


vessels. The papilla (optic disc) contained many smaller blood vessels, but only a few capillaries extended outside the papilla and into the retina for $1-2 \mathrm{~mm}$. These capillaries formed hairpin loops to return to the papilla (Fig. 2a). The remainder of the colugo retina was avascular. When the retina was removed, the remaining fundus showed a uniformly dark pigmentation. There was no indication of a typical choroidal tapetum lucidum lining the fundus.

Transverse semithin sections of the retina showed the conventional layering of mammalian retinae (Fig. 2b). The ONL contained 6-8 tiers of photoreceptor somata and was the thickest of the layers, which is typical for the roddominated retinae of nocturnal mammals. Total retinal thickness was about $170 \mu \mathrm{m}$, as measured in cryostat sections of mid-peripheral to peripheral retina. Because of the tissue shrinkage during Epon embedding, the section shown in Fig. $2 \mathrm{~b}$ appears somewhat thinner.

\section{Photoreceptor Characteristics}

The rod dominance is obvious in sections where the rods are labeled by a rod opsin-specific antibody (Fig. 3). As common in mammals, the rod opsin antibody rho4D2 labeled the entire photoreceptors including their somata. The latter fill the ONL, and the rod outer segments form a continuous lawn at the outer retinal surface. Rod densities were estimated from counts of rod somata in vertical cryostat sections of mid-peripheral retina, immunolabeled for rod opsin. They were in the range of $200,000-250,000 \mathrm{~mm}^{-2}$. With cone densities in the range of 2,500-11,800 $\mathrm{mm}^{-2}$ (see below and Table 1), estimated total photoreceptor densities are about 203,000-262,000 $\mathrm{mm}^{-2}$. Accordingly, rods make up
95-99\% of colugo photoreceptors, which is characteristic of nocturnal mammals. However, due to the limited thickness of avascular retinae, the absolute rod density is uncharacteristically low for a nocturnal mammal (see "Discussion" and Supplemental Material).

The colugo retina contains a consistent population of cones, comprising $1-5 \%$ of the photoreceptors. In the temporal quadrant, cone densities were between 2,500 and $5,400 \mathrm{~mm}^{-2}$, with no clear peak that would indicate a central area, nor a consistent central-peripheral density gradient. In sample fields from dorsal periphery, cone densities were $7,500-8,000 \mathrm{~mm}^{-2}$, and in fields from ventral periphery $7,800-11,800 \mathrm{~mm}^{-2}$. Hence it appears that colugo cone densities are higher in peripheral than in
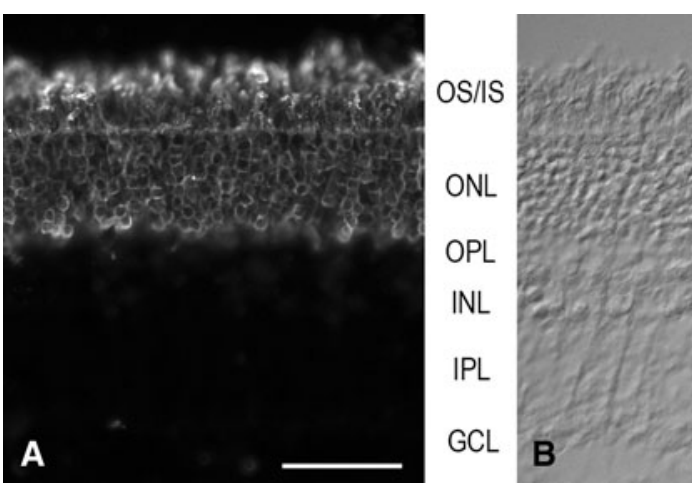

Fig. 3 a Transverse cryostat section immunolabeled for rod opsin. There is a dense population of rods that fill the entire ONL with their somata. b Phase image of part of the field in A to show the retinal layers. OS/IS, photoreceptor outer and inner segments; other abbreviations as in Fig. 2. Scale bar $50 \mu \mathrm{m}$
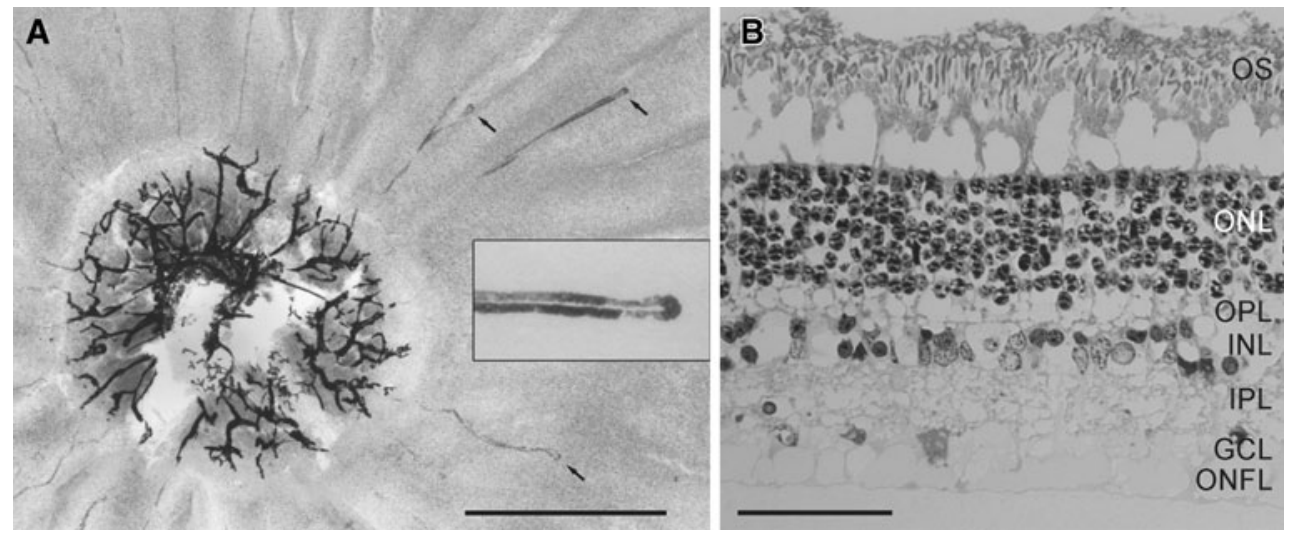

Fig. 2 a Optic disc region of the colugo retina in flat view. Blood vessels were labeled by a DAB reaction. The papilla is densely vascularized, but only a few capillaries extend outside the papilla and into the retina for $1-2 \mathrm{~mm}$. These capillaries form hairpin loops to return to the papilla (three loops arrowed). The remainder of the retina is avascular. The inset shows the hairpin turn of one arrowed capillary at higher magnification. b Colugo retinal layering. Transverse semithin section stained with toluidine blue. Tissue preservation is not perfect, as indicated by the large vacuoles between OS and ONL and in other layers. $O S$ photoreceptor outer segments, $O N L$ outer nuclear layer, $O P L$ outer plexiform layer, $I N L$ inner nuclear layer, $I P L$ inner plexiform layer, $G C L$ ganglion cell layer, $O N F L$ optic nerve fiber layer. Scale bars (a) $1 \mathrm{~mm}$; (b) $50 \mu \mathrm{m}$ 
central retina, albeit the available tissue did not allow compilation of a full topographical map of cone densities.

A large majority of cones expressed the L-opsin (Fig. 4; Supplemental Fig. S1 \& S2). Sampling the densities of $\mathrm{S}$-opsin-expressing cones at various retinal locations yielded about $100-480 \mathrm{~mm}^{-2}$, depending on region. Higher densities were in the mid-peripheral retina. Comparison of L-cone densities and S-cone densities at neighboring positions (cf. Supplemental Fig. S1) showed S-cone proportions of $4-5 \%$ of the cones near the papilla, of 6-9\% in midperipheral retina, and of $2 \%$ in ventral periphery. Unexpectedly, double immunofluorescence revealed that most cones expressing the S-opsin also coexpressed some L-opsin (Fig. 4). Only a small proportion of S-cones were
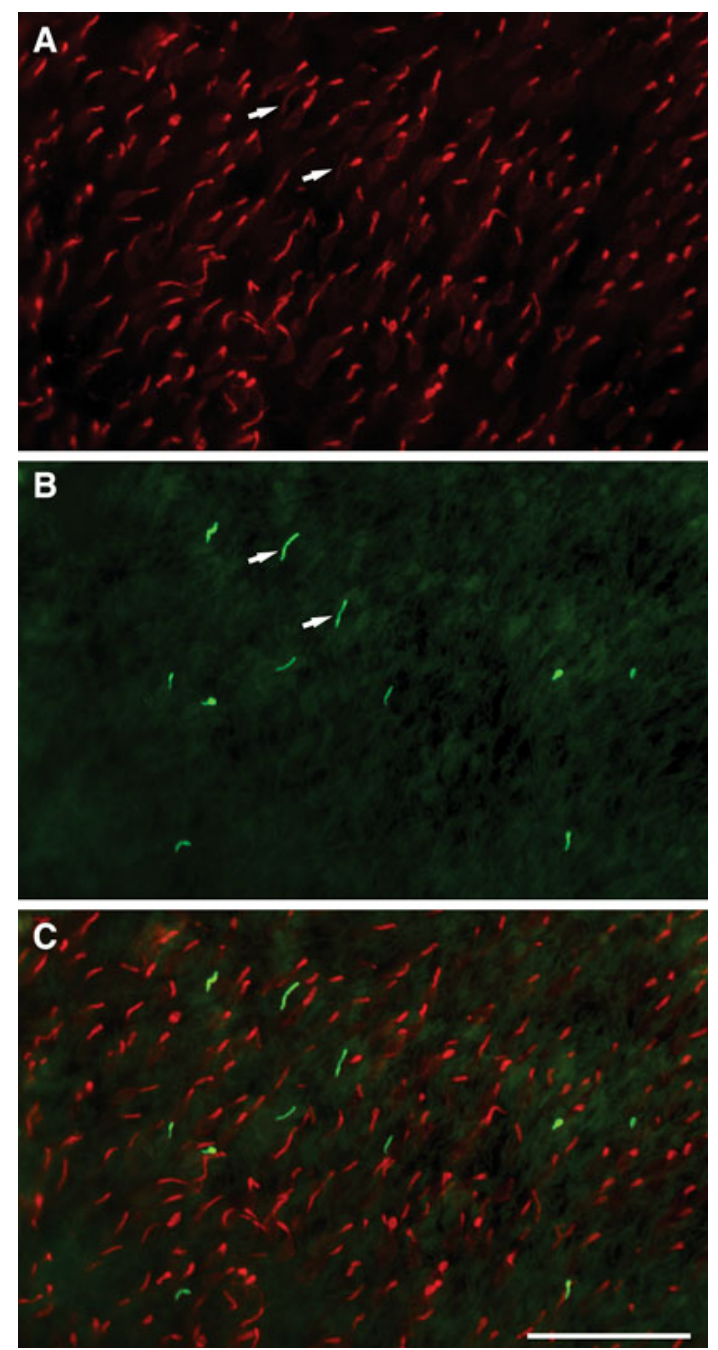

Fig. 4 Double immunofluorescence labeling for S- and L-opsin in a flatmounted piece of ventral peripheral retina. a L-opsin labeling shows a substantial population of cones, the focus is on the outer segments. b S-opsin labeling shows a very sparse population of cones. Each of the S-opsin-expressing outer segments coexpresses some L-opsin (two examples arrowed in $\mathbf{a}$ and $\mathbf{b}$ ). $\mathbf{c}$ Merge of the images in (a) and (b). Scale bar $50 \mu \mathrm{m}$ 'pure' or devoid of L-opsin expression (Supplemental Fig. S2). Hence, the colugo retina contains a majority of pure L-cones, a minority of dual-pigment cones, and a sparse population of pure S-cones. The available material did not allow quantification of the proportion and distribution of pure S-cones.

\section{Cone Opsin Spectral Sensitivities}

In the S-opsin gene, we detected the following residues at six spectral tuning sites: Phe46, Phe49, Thr52, Tyr86, Ile93, and Ala114 (GenBank accession no. KC865781). Of these, we call attention to sites 86 and 93, which have profound effects on the $\lambda_{\max }$ of mammalian S-opsins (Cowing et al. 2002; Parry et al. 2004; Carvalho et al. 2012). Here, the combination of Tyr86 and Ile93, which is also present in cow, indicates an S-opsin pigment with a $\lambda_{\max }$ of $435 \mathrm{~nm}$ (Cowing et al. 2002), $438 \mathrm{~nm}$ (Fasick et al. 2002), or $451 \mathrm{~nm}$ (Jacobs et al. 1998) depending on the methods used. Sequencing of exon 5 of the L-opsin gene revealed Tyr277 and Thr285, indicating an L-opsin pigment with a $\lambda_{\max }$ of $\sim 562 \mathrm{~nm}$ (GenBank accession no. KC865780).

The ancestral primate (and euprimate) is most parsimoniously reconstructed as having an intact $\mathrm{S}$-opsin gene with Phe86 or Tyr86 (Fig. 5) and Va193, Ile93, or Pro93. Estimating the ratio of nonsynonymous to synonymous rates $\left(\mathrm{d}_{\mathrm{N}} / \mathrm{d}_{\mathrm{S}}\right.$ or $\left.\omega\right)$ in a single parameter model (M0) on the tree shown in Supplemental Figure S3 revealed a low overall ratio of 0.39 and evidence of purifying selection across a large proportion of sites under selection and neutral models $\left(\sim 60 \%\right.$ of sites, $\omega_{0}=0.018$; Supplemental Table S1). Such values $(<1)$ are consistent with purifying selection (a result typical of studies of genes with highly conserved functional roles).

\section{Discussion}

The general features of the colugo eye and retina are consistent with the animal's nocturnal activities. For instance, the relatively high rod to cone ratio and thick ONL found in colugos is typical of other nocturnal mammals, including nocturnal primates (Wikler and Rakic 1990). Similarly, nocturnal mammals have distinctive rod cell nuclei, and the inverted nuclear architecture of colugo rod cells speaks to a long history of nocturnality (Solovei et al. 2009; Perry and Pickrell 2010). Yet colugos appear to lack a tapetum lucidum (the structure responsible for the phenomenon of 'eye shine'), as only a dark retinal pigment epithelium was evident. The limited quality of the available material precluded microscopic assessment of a potential retinal tapetum, where the retinal pigment epithelial cells 


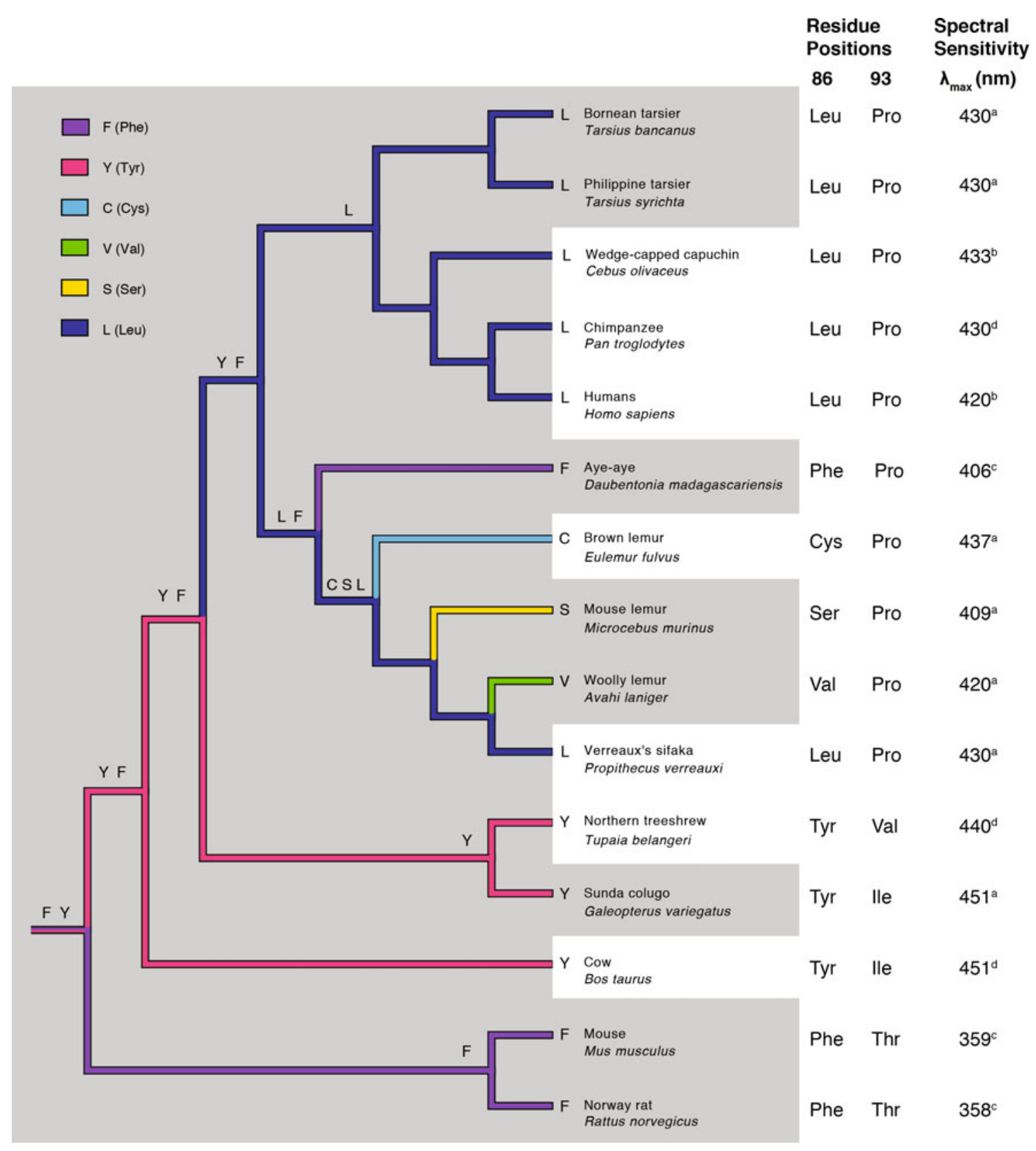

Fig. 5 Composite tree topology of euarchontan S-opsin genes with mammalian outgroups. The $\lambda_{\max }$ of each S-opsin is shown on the basis of DNA sequence $\left({ }^{\mathrm{a}}\right)$, microspectrophotometry $\left(^{\mathrm{b}}\right)$, in vitro expression $\left({ }^{\mathrm{c}}\right.$ ) or electroretinogram $\left({ }^{\mathrm{d}}\right.$ ) (Dartnall et al. 1983; Jacobs and Neitz 1986; Neitz et al. 1991; Jacobs et al. 1996b, 1998; Yokoyama et al. 1998; Tan and Li 1999; Parry et al. 2004; Tan et al. 2005; Carvalho et al. 2012; present study). The tree shows the most probable amino acid state at each ancestral node based on their inferred likelihood at site 86 in the context of observed or inferred

contain reflective inclusions or particles. In contrast to choroidal tapeta, a retinal tapetum is rare among mammals, so far only described for fruit bats and the opossum (Ollivier et al. 2004). Unless the colugo has a retinal tapetum, the reddish to yellowish eye-shine seen in some flash photographs of colugos (Lim 2007) might be a reflection activity patterns among living and ancestral species (after Martin 1990). The distinction between nocturnal (gray zone) and diurnal (white zone) activity patterns conveys the prevailing hypothesis of nocturnal primate origins based principally on orbital, dental, and gross functional morphologies (Martin 1990; Cartmill 1992; Heesy and Ross 2001; Ravosa and Savakova 2004; Martin and Ross 2005; Ravosa and Dagosto 2007; Ross and Kirk 2007). The set of states at each node is ordered from most likely to least likely, excluding states with probabilities below $5 \%$

from the highly vascularized choroid, resembling the phenomenon of human 'red eye' in flash photos. Indeed, many truly nocturnal mammals (e.g., nocturnal rodents, Microchiroptera) lack a tapetum, so it is not an indispensable feature of nocturnal eyes. A caveat is that tapetal riboflavin may dissolve quickly in fixative solutions (for 
a discussion, see Kirk 2006). On the other hand, our experience with the choroidal tapeta of many nonprimate mammals is that they remain visible after long fixation.

The observation that the colugo retina is avascular also came as a surprise. The retinae of non-mammalian vertebrates are generally avascular, as are those of the monotremes and many marsupials (Chase 1982). In contrast, most placental mammals have a vascularized retina, suggesting that avascular retinae are a "primitive" feature among mammals (Chase 1982). Notably, primates and treeshrews have vascularized retinae (Johnson 1901; Müller and Peichl 1989), hence the avascularity of the colugo retina might have developed secondarily after the separation of these lineages (Janečka et al. 2007). The potential adaptive advantages of an avascular retina are unknown, but there is an obvious disadvantage: the retinal oxygen supply depends completely on choroidal circulation. Hence the thickness of the avascular retinae is limited by the diffusion distance of oxygen (Chase 1982), or the inner retina uses anaerobic metabolism (e.g., Yu and Cringle 2001; Bentmann et al. 2005). Avascular mammalian retinae have thicknesses $<200 \mu \mathrm{m}$, whereas vascular retinae are in the range of 200-250 $\mu \mathrm{m}$ (Buttery et al. 1991). Reduced thickness is a particular problem for nocturnal species because they depend on a high rod density and hence a thick ONL for adequate low-light vision. Nocturnal mammals with vascularized retinae have 200,000-850,000 rods/ $/ \mathrm{mm}^{2}$ and ONL with up to 14 tiers of rod nuclei (recent summaries: Peichl 2005; Solovei et al. 2009).

Generalizing from these findings and the observation that colugos are 'living fossils' (Ducrocq et al. 1992; Marivaux et al. 2006), its stands to reason that 45 million years of nocturnality might have resulted in a disabled S-opsin gene (Tan et al. 2005). Instead, we show that Sunda colugos have intact S- and L-opsin genes and that both pigments are expressed in the retina. Furthermore, we found signatures consistent with purifying selection on exon 1 of the colugo S-opsin gene. Taken together, these findings challenge the view that $\mathrm{S}$-opsin genes rapidly acquire disabling mutations under nocturnal conditions, as well as the corollary view that nocturnal primates with intact S-opsin genes, such as Daubentonia, evolved from a diurnal ancestor (Tan et al. 2005).

Our findings also fill a crucial phylogenetic void within Euarchonta. As hypothesized by Carvalho et al. (2012), the ancestral primate (and euprimate) is most parsimoniously reconstructed as having an intact S-opsin gene with Phe86 or Tyr86 (Fig. 5) and Val93, Ile93, or Pro93. Either reconstruction indicates ten amino acid substitutions in subsequent lineages of primates and a selective aversion to UV sensitivities (360-400 nm) due to the strict conservation of Pro93 (Fig. 5). A critical test of this reconstruction would involve opsin sequence data from the pen-tailed treeshrew, Ptilocercus lowii, the most basal euarchontan and only nocturnal scandentian (Roberts et al. 2011). On the basis of available data, the S-opsin gene of $P$. lowii, if functional, is predicted to have Phe or Tyr at site 86 (Carvalho et al. 2012). Such findings, along with the present results, would suggest that functional S-opsin genes cannot be used as evidence of recent diurnal ancestry (pace Tan et al. 2005).

Yet an unanswered question remains: for nocturnal colugos, what are the potential adaptive advantages of maintaining functional S-cones? Although cones are a small minority (1-5\%) of photoreceptors in the colugo retina, they appear to be important. All mammals studied to date possess a duplex retina with both rods and cones (Ahnelt and Kolb 2000; Peichl 2005). An explanation for this pattern is that the rod pathway in the mammalian retina 'piggybacks' on the cone pathway and needs the cone system to convey signals to the retinal ganglion cells (review: Wässle 2004). Cone-mediated color vision is also useful when a nocturnal animal extends its activity into the dawn or dusk period, or when it is disturbed during diurnal rest. Colugos are primarily nocturnal, but they often initiate activities under dim twilight (Lim 2007), which is enriched in shorter, purplish wavelengths (Melin et al. 2012). For colugos, the presence of 'pure' S-cones could be advantageous for discriminating color or enhancing contrast under twilight conditions (Melin et al. 2012); however, the unusual coexpression of S- and L-opsin in many of the S-cones might impede these abilities. Another possibility, given the importance of twilight to the photoentrainment of many nocturnal species (Roenneberg and Foster 1997), is that cones with opsin coexpression contribute to irradiance detection. These issues are discussed further in Supplemental Material. We conclude by suggesting that colugos represent a promising avenue of future research for understanding the ecology and evolution of color vision among nocturnal mammals.

Acknowledgments We thank J. Nathans (Baltimore) and R. S. Molday (Vancouver) for supplying opsin antibodies and we are grateful for the skilled technical assistance of Gerlinde Heiß-Herzberger and Davianne Cartwright. We also thank Peter Ng, George H. Perry, Hugh Tan, and Olga Zhaxybayeva for practical support. Permission to export tissues was granted by the Agri-Food \& Veterinary Authority of Singapore (permit nos. 07EP003774, 08EP001381, and 08EP001395). Funding was received from the Raffles Museum of Biodiversity Research (Visiting Research Fellowship), the National Institutes of Health (Ruth L. Kirschstein National Research Service Award no. 5F32GM064287) and the David and Lucile Packard Foundation (Fellowship in Science and Engineering no. 2007-31754) and Research to Prevent Blindness (to M. Neitz).

Open Access This article is distributed under the terms of the Creative Commons Attribution License which permits any use, distribution, and reproduction in any medium, provided the original author(s) and the source are credited. 


\section{References}

Agoramoorthy, G., Sha, C., \& Hsu, M. (2006). Population, diet and conservation of Malayan flying lemurs in altered and fragmented habitats in Singapore. Biodiversity and Conservation, 15, 2177-2185.

Ahnelt, P. K., \& Kolb, H. (2000). The mammalian photoreceptor mosaic-adaptive design. Progress in Retinal and Eye Research, 19, 711-777.

Aimi, M., \& Inagaki, H. (1988). Grooved lower incisors in flying lemurs. Journal of Mammalogy, 69, 138-140.

Arnold, C., Matthews, L. J., \& Nunn, C. L. (2010). The 10kTrees website: A new online resource for primate phylogeny. Evolutionary Anthropology, 19, 114-118. http://www.10ktrees.fas. harvard.edu. Accessed June 4, 2012.

Asenjo, A. B., Rim, J., \& Oprian, D. D. (1994). Molecular determinants of human red/green color discrimination. Neuron, 12, 1131-1138.

Beard, K. C. (1993). Origin and evolution of gliding in early Cenozoic Dermoptera (Mammalia, Primatomorpha). In R. D. E. MacPhee (Ed.), Primates and their relatives in phylogenetic perspective (pp. 63-90). New York: Plenum Press.

Bentmann, A., Schmidt, M., Reuss, S., Wolfrum, U., Hankeln, T., \& Burmester, T. (2005). Divergent distribution in vascular and avascular mammalian retinae links neuroglobin to cellular respiration. Journal of Biological Chemistry, 280, 20660-20665.

Bloch, J. I., Silcox, M. T., Boyer, D. M., \& Sargis, E. J. (2007). New Paleocene skeletons and the relationship of plesiadapiforms to crown-clade primates. Proceedings of the National Academy of Sciences USA, 104, 1159-1164.

Buttery, R. G., Hinrichsen, C. F. L., Weller, W. L., \& Haight, J. R. (1991). How thick should a retina be? A comparative study of mammalian species with and without intraretinal vasculature. Vision Research, 31, 169-187.

Byrnes, G., Libby, T., Lim, N. T.-L., \& Spence, A. J. (2011a). Gliding saves time but not energy in Malayan colugos. Journal of Experimental Biology, 214, 2690-2696.

Byrnes, G., Lim, N. T.-L., \& Spence, A. J. (2008). Take-off and landing kinetics of a free-ranging gliding mammal, the Malayan colugo (Galeopterus variegatus). Proceedings of the Royal Society B, 275, 1007-1013.

Byrnes, G., Lim, N. T.-L., Yeong, C., \& Spence, A. J. (2011b). Sex differences in the locomotor ecology of a gliding mammal, the Malayan colugo (Galeopterus variegatus). Journal of Mammalogy, 92, 444-451.

Calderone, J. B., \& Jacobs, G. H. (1999). Cone receptor variations and their functional consequences in two species of hamster. Visual Neuroscience, 16, 53-63.

Cartmill, M. (1992). New views on primate origins. Evolutionary Anthropology, 1, 105-111.

Carvalho, L. S., Davies, W. L., Robinson, P. R., \& Hunt, D. M. (2012). Spectral tuning and evolution of primate short-wavelength-sensitive visual pigments. Proceedings of the Royal Society B, 279, 387-393.

Chase, J. (1982). The evolution of retinal vascularization in mammals. A comparison of vascular and avascular retinae. Ophthalmology, 89, 1518-1525.

Cowing, J. A., Poopalasundaram, S., Wilkie, S. E., Robinson, P. R., Bowmaker, J. K., \& Hunt, D. M. (2002). The molecular mechanism for the spectral shifts between vertebrate ultravioletand violet-sensitive cone visual pigments. Biochemical Journal, 376, 129-135.

Dartnall, H. J. A., Bowmaker, J. K., \& Mollon, J. D. (1983). Human visual pigments: Microspectrophotometric results from the eyes of seven persons. Proceedings of the Royal Society B, 220, $115-130$.
Davies, W. L. (2011). Adaptive gene loss in vertebrates: Photosensitivity as a model case. In $e L S$. Chichester: John Wiley \& Sons.

Davies, W. L., Collin, S. P., \& Hunt, D. M. (2012). Molecular ecology and adaptation of visual photopigments in craniates. Molecular Ecology, 21, 3121-3158.

Dkhissi-Benyahya, O., Szel, A., Degrip, W. J., \& Cooper, H. M. (2001). Short and mid-wavelength cone distribution in a nocturnal strepsirrhine primate (Microcebus murinus). Journal of Comparative Neurology, 438, 490-504.

Ducrocq, S., Buffetaut, E., Buffetaut-Tong, H., Jaeger, J.-J., Jongkanjanasoontorn, Y., \& Suteethorn, V. (1992). First fossil flying lemur: A dermopteran from the Late Eocene of Thailand. Palaeontology, 35, 373-380.

Dzulhelmi, M., \& Abdullah, M. (2009). Foraging ecology of the Sunda colugo (Galeopterus variegatus) in Bako National Park, Sarawak, Malaysia. Malayan Nature Journal, 61, 285-294.

Fasick, J. I., Applebury, M. L., \& Oprian, D. D. (2002). Spectral tuning in the mammalian short-wavelength sensitive cone pigments. Biochemistry, 41, 6860-6865.

Heesy, C. P., \& Ross, C. F. (2001). Evolution of activity patterns and chromatic vision in primates: Morphometrics, genetics and cladistics. Journal of Human Evolution, 40, 111-149.

Hendrickson, A., Djajadi, H. R., Nakamura, L., Possin, D. E., \& Sajuthi, D. (2000). Nocturnal tarsier retina has both short and long/medium-wavelength cones in an unusual topography. Journal of Comparative Neurology, 424, 718-730.

Hicks, D., \& Molday, R. S. (1986). Differential immunogold-dextran labeling of bovine and frog rod and cone cells using monoclonal antibodies against bovine rhodopsin. Experimental Eye Research, 42, 55-71.

Hunt, D. M., Carvalho, L. S., Cowing, J. A., \& Davies, W. L. (2009). Evolution and spectral tuning of visual pigments in birds and mammals. Philosophical Transactions of the Royal Society B, 364, 2941-2955.

Hunt, D. M., Carvalho, L. S., Cowing, J. A., Parry, J. W. L., Wilkie, S. E., Davies, W. L., et al. (2007). Spectral tuning of shortwavesensitive visual pigments in vertebrates. Photochemistry and Photobiology, 83, 303-310.

Hunt, D. M., Cowing, J. A., Wilkie, S. E., Parry, J. W. L., Poopalasundaram, S., \& Bowmaker, J. K. (2004). Divergent mechanisms for the tuning of shortwave sensitive visual pigments in vertebrates. Photochemical \& Photobiological Sciences, 3, 713-720.

Jacobs, G. H. (2008). Primate color vision: A comparative perspective. Visual Neuroscience, 25, 619-633.

Jacobs, G. H. (2013). Losses of functional opsin genes, shortwavelength cone photopigments, and color vision - a significant trend in the evolution of mammalian vision. Visual Neuroscience. doi:10.1017/S0952523812000429.

Jacobs, G. H., Deegan, J. F., \& Moran, J. L. (1996a). ERG measurements of the spectral sensitivity of common chimpanzee (Pan troglodytes). Vision Research, 36, 2587-2594.

Jacobs, G. H., Deegan, J. F., \& Neitz, J. A. Y. (1998). Photopigment basis for dichromatic color vision in cows, goats, and sheep. Visual Neuroscience, 15, 581-584.

Jacobs, G. H., \& Neitz, J. (1986). Spectral mechanisms and color vision in the tree shrew (Tupaia belangeri). Vision Research, 26, 291-298.

Jacobs, G. H., Neitz, M., \& Neitz, J. (1996b). Mutations in S-cone pigment genes and the absence of colour vision in two species of nocturnal primate. Proceedings of the Royal Society B, 263, 705-710.

Janečka, J. E., Helgen, K. M., Lim, N. T.-L., Baba, M., Izawa, M., Boeadi, et al. (2008). Evidence for multiple species of Sunda colugo. Current Biology, 18, R1001-R1002.

Janečka, J. E., Miller, W., Pringle, T. H., Wiens, F., Zitzmann, A., Helgen, K. M., et al. (2007). Molecular and genomic data identify the closest living relative of primates. Science, 318, 792-794. 
Johnson, G. L. (1901). Contributions to the comparative anatomy of vertebrates, chiefly based on ophthalmoscopic examination. Philosophical Transactions of the Royal Society London B, 194, 1-82.

Jones, D. T., Taylor, W. R., \& Thornton, J. M. (1992). The rapid generation of mutation data matrices from protein sequences. Computer Applications in Biosciences, 8, 275-282.

Kawamura, S., \& Kubotera, N. (2004). Ancestral loss of short wavesensitive cone visual pigment in lorisiform prosimians, contrasting with its strict conservation in other prosimians. Journal of Molecular Evolution, 58, 314-321.

Kirk, E. C. (2006). Eye morphology in cathemeral lemurids and other mammals. Folia Primatologica, 77, 27-49.

Lim, N. T.-L. (2007). Colugo: The flying lemur of South-East Asia. Singapore: Draco.

Lim, N. T.-L., Giam, X., Byrnes, G., \& Clements, G. R. (2013). Occurrence of the Sunda colugo (Galeopterus variegatus) in the tropical forests of Singapore: A Bayesian approach. Mammalian Biology, 78, 63-67.

Lim, N. T.-L., \& Ng, P. K. L. (2010). Population assessment methods for the Sunda colugo Galeopterus variegatus (Mammalia: Dermoptera) in tropical forests and their viability in Singapore. Raffles Bulletin of Zoology, 58, 157-164.

Marivaux, L., Bocat, L., Chaimanee, Y., Jaeger, J.-J., Marandat, B., Srisuk, P., et al. (2006). Cynocephalid dermopterans from the Palaeogene of South Asia (Thailand, Myanmar and Pakistan): Systematic, evolutionary and palaeobiogeographic implications. Zoologica Scripta, 35, 395-420.

Martin, R. D. (1990). Primate origins and evolution: A phylogenetic reconstruction. Princeton: Princeton University Press.

Martin, R. D. (2008). Colugos: Obscure mammals glide into the evolutionary limelight. Journal of Biology, 7, 1-5.

Martin, R. D., \& Ross, C. F. (2005). The evolutionary and ecological context of primate vision. In J. Kremers (Ed.), The primate visual system (pp. 1-36). Chichester: Wiley.

Melin, A. D., Matsushita, Y., Moritz, G. L., Dominy, N. J., Kawamura, S. (2013). Inferred L/M cone opsin polymorphism of ancestral tarsiers sheds dim light on the origin of anthropoid primates. Proceedings of the Royal Society B, 280, 20130189.

Melin, A. D., Moritz, G. L., Fosbury, R. A. E., Kawamura, S., \& Dominy, N. J. (2012). Why aye-ayes see blue. American Journal of Primatology, 74, 185-192.

Mendoza, M. M., \& Custodio, C. C. (2000). Field observations on the Philippine flying lemur (Cynocephalus volans). In R. L. Goldingay \& J. Scheibe (Eds.), Biology of gliding mammals (pp. 273-280). Fürth: Filander Verlag.

Merbs, S. L., \& Nathans, J. (1992). Absorption spectra of human cone pigments. Nature, 356, 433-435.

Meredith, R. W., Janečka, J. E., Gatesy, J., Ryder, O. A., Fisher, C. A., Teeling, E. C., et al. (2011). Impacts of the Cretaceous terrestrial revolution and $\mathrm{KPg}$ extinction on mammal diversification. Science, 334, 521-524.

Müller, B., Glösmann, M., Peichl, L., Knop, G. C., Hagemann, C., \& Ammermüller, J. (2009). Bat eyes have ultraviolet-sensitive cone photoreceptors. PLoS ONE, 4, e6390.

Müller, B., Goodman, S. M., \& Peichl, L. (2007). Cone photoreceptor diversity in the retinas of fruit bats (Megachiroptera). Brain, Behavior and Evolution, 70, 90-104.

Müller, B., \& Peichl, L. (1989). Topography of cones and rods in the tree shrew retina. Journal of Comparative Neurology, 282, 581-594.

Müller, B., \& Peichl, L. (2005). Retinal cone photoreceptors in microchiropteran bats. Investigative Ophthalmololgy \& Visual Science, 46, E-Abstract 2259.

Nei, M., \& Kumar, S. (2000). Molecular evolution and phylogenetics. New York: Oxford University Press.
Neitz, J., \& Neitz, M. (2011). The genetics of normal and defective color vision. Vision Research, 51, 633-651.

Neitz, M., Neitz, J., \& Jacobs, G. (1991). Spectral tuning of pigments underlying red-green color vision. Science, 252, 971-974.

O’Leary, M. A., Bloch, J. I., Flynn, J. J., Gaudin, T. J., Giallombardo, A., Giannini, N. P., et al. (2013). The placental mammal ancestor and the post-K-Pg radiation of placentals. Science, 339, 662-667.

Ollivier, F. J., Samuelson, D. A., Brooks, D. E., Lewis, P. A., Kallberg, M. E., \& Komáromy, A. M. (2004). Comparative morphology of the tapetum lucidum (among selected species). Veterinary Ophthalmology, 7, 11-22.

Parry, J. W. L., Poopalasundaram, S., Bowmaker, J. K., \& Hunt, D. M. (2004). A novel amino acid substitution is responsible for spectral tuning in a rodent violet-sensitive visual pigment. Biochemistry, 43, 8014-8020.

Peichl, L. (1992). Morphological types of ganglion cells in the dog and wolf retina. Journal of Comparative Neurology, 324, $590-602$.

Peichl, L. (2005). Diversity of mammalian photoreceptor properties: Adaptations to habitat and lifestyle? Anatomical Record A, 287, 1001-1012.

Peichl, L., Chavez, A. E., Ocampo, A., Mena, W., Bozinovic, F., \& Palacios, A. G. (2005). Eye and vision in the subterranean rodent cururo (Spalacopus cyanus, Octodontidae). Journal of Comparative Neurology, 486, 197-208.

Peichl, L., Rakotondraparany, F., \& Kappeler, P. (2001). Photoreceptor types and distributions in nocturnal and diurnal Malagasy primates. Investigative Ophthalmology \& Visual Science, 42, S48.

Perelman, P., Johnson, W. E., Roos, C., Seuánez, H. N., Horvath, J. E., Moreira, M. A. M., et al. (2011). A molecular phylogeny of living primates. PLoS Genetics, 7, e1001342.

Perry, G. H., Martin, R. D., \& Verrelli, B. C. (2007). Signatures of functional constraint at aye-aye opsin genes: The potential of adaptive color vision in a nocturnal primate. Molecular Biology and Evolution, 24, 1963-1970.

Perry, G. H., \& Pickrell, J. K. (2010). A rod cell marker of nocturnal ancestry. Journal of Human Evolution, 58, 207-210.

Ravosa, M. J., \& Dagosto, M. (2007). Primate origins: Adaptations and evolution. New York: Springer.

Ravosa, M. J., \& Savakova, D. G. (2004). Euprimate origins: The eyes have it. Journal of Human Evolution, 46, 355-362.

Roberts, T. E., Lanier, H. C., Sargis, E. J., \& Olson, L. E. (2011). Molecular phylogeny of treeshrews (Mammalia: Scandentia) and the timescale of diversification in Southeast Asia. Molecular Phylogenetics and Evolution, 60, 358-372.

Roenneberg, T., \& Foster, R. G. (1997). Twilight times: Light and the circadian system. Photochemistry and Photobiology, 66, $549-561$.

Rose, K. D., Walker, A., \& Jacobs, L. L. (1981). Function of the mandibular tooth comb in living and extinct mammals. Nature, 289, 583-585.

Ross, C. F., \& Kirk, E. C. (2007). Evolution of eye size and shape in primates. Journal of Human Evolution, 52, 294-313.

Rossie, J. B., Ni, X., \& Beard, C. (2006). Cranial remains of an Eocene tarsier. Proceedings of the National Academy of Sciences USA, 103, 4381-4385.

Saitou, N., \& Nei, M. (1987). The neighbor-joining method: A new method for reconstructing phylogenetic trees. Molecular Biology and Evolution, 4, 406-425.

Schleich, C. E., Vielma, A., Glösmann, M., Palacios, A. G., \& Peichl, L. (2010). Retinal photoreceptors of two subterranean tuco-tuco species (Rodentia, Ctenomys): Morphology, topography, and spectral sensitivity. Journal of Comparative Neurology, 518, 4001-4015. 
Shi, Y., Radlwimmer, F. B., \& Yokoyama, S. (2001). Molecular genetics and the evolution of ultraviolet vision in vertebrates. Proceedings of the National Academy of Sciences USA, 98, 11731-11736.

Simpson, G. G. (1945). The principles of classification and a classification of mammals. Bulletin of the American Museum of Natural History, 85, 1-350.

Solovei, I., Kreysing, M., Lanctôt, C., Kösem, S., Peichl, L., Cremer, T., et al. (2009). Nuclear architecture of rod photoreceptor cells adapts to vision in mammalian evolution. Cell, 137, 356-368.

Stern, A., Doron-Faigenboim, A., Erez, E., Martz, E., Bacharach, E., \& Pupko, T. (2007). Selecton: Advanced models for detecting positive and purifying selection using a Bayesian inference approach. Nucleic Acids Research, 35, W506-W511.

Tamura, K., Peterson, D., Peterson, N., Stecher, G., Nei, M., \& Kumar, S. (2011). MEGA5: Molecular evolutionary genetics analysis using maximum likelihood, evolutionary distance, and maximum parsimony methods. Molecular Biology and Evolution, 28, 2731-2739.

Tan, Y., \& Li, W.-H. (1999). Trichromatic vision in prosimians. Nature, 402, 36

Tan, Y., Yoder, A. D., Yamashita, N., \& Li, W.-H. (2005). Evidence from opsin genes rejects nocturnality in ancestral primates. Proceedings of the National Academy of Sciences USA, 102, 14712-14716.

Veilleux, C. C., Louis, E. E., \& Bolnick, D. A. (2013). Nocturnal light environments influence color vision and signatures of selection on the OPN1SW opsin gene in nocturnal lemurs. Molecular Biology and Evolution. doi:10.1093/molbev/mst058.

Wang, Y., Macke, J. P., Merbs, S. L., Zack, D. J., Klaunberg, B., Bennett, J., et al. (1992). A locus control region adjacent to the human red and green visual pigment genes. Neuron, 9, 429-440.

Wang, D., Oakley, T., Mower, J., Shimmin, L. C., Yim, S., Honeycutt, R. L., et al. (2004). Molecular evolution of bat color vision genes. Molecular Biology and Evolution, 21, 295-302.
Wässle, H. (2004). Parallel processing in the mammalian retina. Nature Reviews Neuroscience, 5, 747-757.

Wikler, K., \& Rakic, P. (1990). Distribution of photoreceptor subtypes in the retina of diurnal and nocturnal primates. Journal of Neuroscience, 10, 3390-3401.

Wischusen, E. W., Ingle, N., \& Richmond, M. E. (1994). Rate of digesta passage in the Philippine flying lemur, Cynocephalus volans. Journal of Comparative Physiology B, 164, 173-178.

Wischusen, E. W., \& Richmond, M. E. (1998). Foraging ecology of the Philippine flying lemur (Cynocephalus volans). Journal of Mammalogy, 79, 1288-1295.

Yang, Z. (1997). PAML: A program package for phylogenetic analysis by maximum likelihood. Computer Applications in the Biosciences, 13, 555-556.

Yang, Z., \& Nielsen, R. (1998). Synonymous and nonsynonymous rate variation in nuclear genes of mammals. Journal of Molecular Evolution, 46, 409-418.

Yokoyama, S., \& Radlwimmer, F. B. (2001). The molecular genetics and evolution of red and green color vision in vertebrates. Genetics, 158, 1697-1710.

Yokoyama, S., Radlwimmer, F. B., \& Kawamura, S. (1998). Regeneration of ultraviolet pigments of vertebrates. FEBS Letters, 423, 155-158.

Yu, D. Y., \& Cringle, S. J. (2001). Oxygen distribution and consumption within the retina in vascularised and avascular retinas and in animal models of retinal disease. Progress in Retinal and Eye Research, 20, 175-208.

Zhao, H., Rossiter, S. J., Teeling, E. C., Li, C., Cotton, J. A., \& Zhang, S. (2009a). The evolution of color vision in nocturnal mammals. Proceedings of the National Academy of Sciences USA, 106, 8980-8985.

Zhao, H., Xu, D., Zhou, Y., Flanders, J., \& Zhang, S. (2009b). Evolution of opsin genes reveals a functional role of vision in the echolocating little brown bat (Myotis lucifugus). Biochemical Systematics and Ecology, 37, 154-161. 